\title{
EL LIBRO HOMOSEXUALIDAD DEL DR. MARTÍN DE LUCENAY: ENTRE EL CONOCIMIENTO CIENTÍFICO Y LA RECEPCIÓN PÚBLICA DE LA CIENCIA SEXOLÓGICA EN ESPAÑA A PRINCIPIOS DEL SIGLO XX ${ }^{1}$
}

por

\section{RICHARD CLEMINSON}

Universidad de Leeds

RESUMEN: Este artículo analiza el impacto de las ideas del Dr. Ángel Martín de Lucenay expresadas en su libro "Homosexualidad» de 1933. Rechazando una división tajante entre lo "experto" y lo "popular» y refiriéndose a las teorías de la construcción del conocimiento científico, el autor examina el contenido y la recepción de los postulados de dicho doctor en cuanto a la bomosexualidad masculina, fenómeno que por múltiples razones científicas, sociales $y$ culturales vino a ser de relevancia en medios expertos $y$ populares de la época.

PAlabras Clave: Homosexualidad. Sexología. Recepción. España.

ABSTRACT: This article analyses the impact of the ideas of Dr. Angel Martin de Lucenay as expressed in his book "Homosexualidad» published in 1933. The article rejects any clear dividing line between «expert» thought and "popular» conceptions and by reference to a number of theories on the construction of scientific knowledge the author examines the content and reception of Martin de Lucenay's work and places it within the multiple scientific, social and cultural factors that made bomosexuality an important issue at the time.

KEY WORDS: Homosexuality. Sexology. Reception. Spain.

\footnotetext{
1 Este trabajo se realizó durante una estancia en Granada entre 2002 y 2003 a raíz de una beca de Historia de la Medicina de la Wellcome Trust, concedida para investigar la medicalización de la homosexualidad masculina en España. Agradezco el apoyo de dicha Trust. Por otro lado, me gustaría dedicar este trabajo a JFVR.
} 
«Se refiere por el autor el caso de un médico heterosexual muy aficionado a las mujeres, el cual recibió la consulta de un invertido que, deseoso de curarse, expuso al médico todas las circunstancias de su inversión sin omitir lo referente al carácter de sus sensaciones eróticas. El propio médico confiesa que aquella confesión le impresionó tanto, que llegó, en virtud de la sugestión, al extremo de practicar la homosexualidad, cuyo vicio no consiguió desarraigar en muchos años»².

La relación entre el conocimiento científico y su recepción en el mundo más amplio de la cultura constituye una problemática que plantea complejos retos para el historiador. Por un lado, se ha reconocido que en el proceso de construcción del conocimiento científico influyen muchos factores o valores tanto sociales como metodológicos de la propia ciencia y que esos valores pueden constituir un elemento integral en el proceso de construcción de ese conocimiento. Por otro lado, ya se ha pasado a una crítica sofisticada que niega un proceso de transmisión lineal entre los conocimientos científicos «expertos» y la recepción por parte del público de esos mismos conocimientos, según el cual uno tomaría el papel de «exportador» de ideas (normalmente la ciencia) y el otro el papel de «importador» (normalmente la esfera popular).

Existe una extensa literatura acerca de la construcción social de la ciencia. De más utilidad para aplicar a la historia de la sexualidad para este autor han sido los «Social Studies of Science», los análisis de la ciencia eugénica, y la crítica feminista cara a la ciencia ${ }^{3}$. Por "popular", entiendo el público general, fuera de las esferas expertas y privilegiadas de la Universidad, organismos o instituciones estatales. Desde luego, esta división es todo menos que tajante y, además, es problemática, pero creo que sirve aquí como base de partida para examinar el tema del artículo.

Se ha reconocido que en el proceso de construcción del conocimiento científico impera un proceso mediador en el que influyen no sólo los modos en que cualquier información científica es presentada a su público, sino que se ha reconocido también que son importantes las condiciones sociales en que se realiza este proceso. De ahí, si lo popular no es únicamente una correa de transmisión para los conocimientos provenientes de la elite científica, constituye, o puede constituir, un lugar desde donde emanan ideas y teorías que luego son incorporadas en las esferas académicas y en las prácticas expertas. Bajo esta óptica, lo popular no constituye un actor pasivo; más bien puede contribuir de forma activa tanto a la propia textura como a la divulgación de los conocimientos científicos.

2 Martín De Lucenay, Dr. A.: Homosexualidad, Madrid, Editorial Fénix (Temas sexuales, $\mathrm{n}^{\circ}$ 31), 1933, p. 83.

3 Ver HARDING, Sandra: The Science Question in Feminism, Milton Keynes, Open University Press, 1986; KNORR-CETINA, Karin: The manufacture of knowledge: an essay on the constructivist and contextual nature of science, Oxford, Pergamon Press, 1981; LONGINO, Helen E.: Science as social knowledge: values and objectivity in scientific inquiry, Princeton, Princeton University Press, 1990; STEPAN, Nancy L.: "The Hour of Eugenics»: race, gender, and nation in Latin America, Ithaca-London, Cornell University Press, 1991.

Hispania, LXIV/3, núm. 218 (2004) 961-986 
Siguiendo esta línea de argumentación, la recepción de la ciencia varía según el grupo social o político en que tiene impacto. Más radicalmente todavía, se podría argüir que lo que se acepta como «ciencia» es algo que depende - por lo menos en parte- del contexto socio-político en que el proceso de difusión se realiza. La tentativa de perfilar un espacio claramente diferenciado entre la "ciencia propiamente dicha" y la "pseudo-ciencia» puede entenderse como un intento de distinguir entre varios sistemas de conocimiento y su aceptación según los parámetros de la época en que son divulgados, o bien como una justificación de la supuesta objetividad de la propia ciencia.

Los estudios acerca de la recepción de ideas científicas han experimentado un auge en los últimos años, reflejando los avances hechos en la historia social y la historia de la ciencia y han respondido ante el reto que han supuesto algunas teorías posmodernas, en particular las críticas feministas y los estudios sociales de la ciencia. Sin embargo, mientras que hay estudios que plantean, por ejemplo, los límites dibujados entre la brujería y la ciencia en siglos más remotos, otros que tratan de la recepción del darwinismo, de la eugenesia, o de las teorías pertinentes al alcoholismo, sobre la recepción popular de ideas acerca de la sexualidad apenas se dan los primeros pasos, por lo menos en España, a pesar de la aparición de un fuerte impulso en este sentido en los últimos años ${ }^{4}$. La mayor parte de las tesis académicas que se han escrito acerca de la historia de la sexualidad se concentra en los años más recientes sobre todo después de la transición $\mathrm{o}$, por ejemplo, en los procesos inquisitoriales ${ }^{5}$.

Sin embargo, el terreno de la sexualidad nos ofrece un campo muy fértil en cuanto a la posibilidad de trazar tanto la influencia de valores religiosos o morales en la ciencia como la relación entre el conocimiento científico y la recepción popular. Dos autores han escrito recientemente acerca de las posibilidades que un estudio de la sexualidad nos puede ofrecer en este sentido:

\begin{abstract}
«Posiblemente, uno de los aspectos de la medicina en donde queda patente con mayor claridad la influencia de los valores sea en el establecimiento de especies morbosas. Y, debido a su especial ductilidad, quizá sea en las especies morbosas relacionadas con la esfera sexual en donde mejor se deje ver la impronta de los valores sobre un hecho del campo médico cual es la configuración de las entidades nosológicas»6.
\end{abstract}

4 Un estado de cuestión en los estudios acerca de la sexualidad en VÁzQuEZ García, Francisco: «Historia de la sexualidad en España: problemas metodológicos y estado de la cuestión», Hispania (Madrid), $\mathrm{n}^{\mathrm{a}} 194$ (1996), pp. 1007-1035.

5 Unas excepciones incluyen PÉREZ LÓPEZ, Jesús: El discurso pedagógico relativo a la sexualidad en España (1940-1962), Tesis doctoral (Departamento de Sociología), Madrid, Editorial UCM, 1993 y SEOANE, José Benito: La Pasión y la Norma. Una genealogía de la moral sexual infantil en la España del siglo XIX, Tesis doctoral, Universidad de Cádiz, 2001.

6 Perdiguero Gil, Enrique y GonZÁlez de PABlo, Ángel: «Los valores morales de la higiene. El concepto de onanismo como enfermedad según Tissot y su tardía introducción en España», Dynamis

Hispania, LXIV/3, núm: 218 (2004) 961-986 
El análisis de esta coyuntura entre lo científico y lo laico (en sentido no especialista) constituye uno de los propósitos principales de este artículo. Para entrar en los debates arriba trazados, me voy a referir a una forma de literatura que, aunque bastante especializada y con una base en las ciencias sexológicas, era dirigida a un lector curioso no especialista y era caracterizada por ser una literatura de difusión sexológica "científico-popular» que tanta influencia tuvo en España y en otros países europeos a principios del siglo $\mathrm{XX}^{7}$.

Pensamos que es posible demostrar que tanto en lo que se refiere al formato de este tipo de publicación, al precio de cada ejemplar, al lenguaje en que estaba escrito y al hecho de que los autores de esta literatura ilustraban su argumento con casos sacados del mundo real, la literatura de difusión sexológica ejemplifica la recepción de la ciencia en el mundo más amplio. No obstante, sería necesario un estudio mucho más detallado de la difusión sexológica del tiempo para calibrar su recepción, proyecto éste que todavía está por hacer ${ }^{8}$.

Específicamente, nos referiremos en este artículo a un libro que constituyó parte de la obra del doctor A. Martín de Lucenay, publicado por la Editorial Fénix de Madrid en 1933 en el marco de la colección «Temas sexuales»9. La colección consistía en un total de sesenta libros de cerca de noventa páginas cada uno sobre distintos aspectos de la vida sexual de los seres humanos. Esta producción tan prodigiosa se realizó en un periodo muy corto de tres años, entre 1932 y 1934 . Analizaremos más concretamente el número 31 de la serie de Lucenay que se titulaba Homosexualidad.

Este artículo abarcará tres objetivos principales. Ofreceremos primero una contextualización general de la sexología española para situar la obra de Lucenay en los primeros años de la Segunda República. Analizaremos después la taxonomía de la homosexualidad que emplea Lucenay en su libro, y el marco explicativo que el autor ofrece para indagar en las «causas» psíquicas o biológicas de la homosexualidad. Este deseo del poder médico de producir la verdad sobre los homosexuales tendría su efecto jurídico, o por lo menos una propuesta de intervención jurídica, como veremos más adelante.

(Granada), na 10 (1990), p. 132. Ver HuerTas GARCíA-AlejO, R: «El concepto de la «perversión» sexual en la medicina positivista", Asclepio (Madrid), vol. 42 (1990), n 2, pp. 89-99.

7 Ver, por ejemplo, HALL, Lesley: Hidden Anxieties: male sexuality, 1900-1950, Cambridge, Polity Press, 1991.

8 Este artículo se encaja dentro de un proyecto de más envergadura acerca de la historia de la homosexualidad masculina que estoy desarrollando con Francisco Vázquez García. Las razones por las cuales se trata solamente la homosexualidad masculina son abordadas en CLEMINSON, Richard y VÁZQUEZ GARCíA, Francisco: «Los Invisibles: hacia una historia de la homosexualidad masculina en España, 1840-2000", International Journal of Iberian Studies, vol. 13 (2000), $\mathrm{n}^{\circ} 3$, pp. 167-181.

9 Sobre la editorial Fénix, ver SANTONJA, Gonzalo: La República de los libros. El nuevo libro popular de la II República, Barcelona, Anthropos, 1989, pp. 153-179 (sobre Martín de Lucenay, pp. 161-174). Lucenay dirigió otras colecciones de divulgación sexual, como «Cultura física y sexual» publicada por la Editorial Cisne en 1936.

Hispania, LXIV/3, núm. 218 (2004) 961-986 
Lucenay no preconizaba para los «verdaderos homosexuales» una intervención jurídica represora. De acuerdo con muchos otros comentaristas en la época señalada, Lucenay veía la homosexualidad ("verdadera») como una perversión del instinto sexual debida a razones biológicas o psíquicas (o a las dos a la vez en un complejo juego etiológico) y una práctica que necesitaba ser tratada con un cierto grado de simpatía y con conocimiento científico por ser un tema de interés para la sociedad. Esta vertiente progresista - hasta cierto punto- de la razón sexológica era ya para los tiempos que corrían bastante común y podía notarse en la obra de individuos tan dispares como, por ejemplo, Gregorio Marañón o Félix Martí Ibáñez. El Dr. Gregorio Marañón es probablemente el científico español de más importancia y calado en respecto de la homosexualidad, habiendo construido una teoría que, a pesar de su ecléctico uso de teorías europeas, era la que más se acerca a un planteamiento específicamente español en cuanto a la homosexualidad. Su obra más importante es Los estados intersexuales en la especie bumana (Morata, Madrid), de 1929. El Dr. Félix Martí Ibáñez era un médico libertario y divulgador del tema sexual, a veces con marcada énfasis libertaria.

Un tercer objetivo de este artículo consistirá en analizar la representación de la subcultura homosexual que Lucenay proporciona, para asesorar el complejo juego entre la representación científica y la «realidad». Este apartado del trabajo será algo más tentativo.

\section{LA OBRA DE MARTÍN DE LUCENAYY SU LUGAR EN LA TRADICIÓN SEXOLÓGICA DE DIVULGACIÓN}

Para entender la obra de Martín de Lucenay, es necesario situarla dentro de una tradición que fue establecida en España a finales del siglo XX por escritores como Suárez Casañ y Amancio Peratoner, autores que empezaron a examinar el tema sexual de una manera accesible para personas no necesariamente expertas en la ciencia sexológica o psiquiátrica pero que tenían interés por el asunto ${ }^{10}$. La literatura de este tipo difiere notablemente de los tratados de medicina legal o forense de la segunda mitad del siglo XIX o incluso de principios del XX y en este sentido marca un giro tanto cualitativo como cuantitativo en la literatura sobre la sexualidad. La literatura de divulgación sexual no cesó de producirse una vez terminada la Guerra Civil. Aunque dio otro giro en cuanto a su contenido y bases morales, en el franquismo se abrió otra etapa, fuertemente influenciada por el nacional-catolicismo ${ }^{11}$.

\footnotetext{
10 AmezÚA, Efigenio: «Cien años de temática sexual en España: 1850-1950. Repertorio y Análisis", Revista de Sexología (Madrid), nº 48 (1991), pp. 1-197.

11 VÁzQUez GARCía, Francisco y MORENO MENGÍBAR, Andrés: Sexo y Razón: Una genealogía de la moral sexual en España (siglos XVI-XX), Madrid, Akal, 1997, pp. 171-179.
}

Hispania, LXIV/3, núm. 218 (2004) 961-986 
El auge de pequeñas obras divulgativas de información sexual, además de ser un fenómeno hasta cierto punto europeo, fue acompañado en España por la articulación y, en alguna medida, la institucionalización de las ciencias sexuales como la eugenesia y el psicoanálisis ${ }^{12}$, y por la aparición de la novela corta - frívola o seria - que trataba temas del amor, la convivencia o la sexualidad más o menos marginada. Un componente del fenómeno modernizador de los años veinte en España fue la publicación de colecciones como «La Novela de Hoy» o la «Novela de Amor», series que "crearon o reflejaron una voracidad lectora de clases no intelectuales que estaban ávidas de nuevas sensaciones o de vicios secretos» ${ }^{13}$. En otra categoría, una contestación a la «frivolidad» de estas colecciones, sería «La Novela Ideal» anarquista, que abogaba por un tratamiento «serio» del tema del amor, pero que bebía de la misma fuente: el desbordante interés por la sexualidad en este periodo.

Las obras de Lucenay, por lo tanto, se encuadran perfectamente en la tradición de diseminación científico-popular de la sexualidad nacida a finales del siglo XIX y en el periodo del auge de la atención científica y pública hacia la sexualidad en torno a los años 1920-1936, alentada además por la llegada de la República, no sólo por su gran producción sino también porque el propósito de divulgar el conocimiento sexológico se hizo explícito: el subtítulo de la colección en que aparecieron sus sesenta libros se denominaba «Biblioteca de Divulgación Sexual».

Del autor, desgraciadamente, tenemos poca información. Esto en sí no es especialmente extraño ya que hubo bastantes divulgadores de la temática sexual que no dejaron muchos rastros en una época caracterizada por una gran difusión de la palabra impresa de todo tipo. La figura de Lucenay parece ser, hasta cierto grado, algo obscura, no sólo por la falta de información disponible. Santonja, por ejemplo, lo describe como "pintoresco, capaz y atrevido personaje", que se había auto-concedido el título de diplomado en Sexología por la Escuela Libre de Sexología de Río de Janeiro, entidad que resultaría inexistente ${ }^{14}$. Otro calificativo que llevaba el autor era el de ser, según la portada trasera de sus libros, exagregado «en las misiones de Lucha contra la trata de blancas en Sudamérica y Tráfico de estupefacientes en Extremo Oriente» ${ }^{15}$.

12 Cleminson, Richard M. y AmEZÚA, Efigenio: «Spain: the political and social context of sex reform in the late nineteenth and early twentieth centuries", en EDER, F. X., HALL, L. y HEKMA, G. (eds.): Sexual Cultures in Europe. National Histories, Manchester, Manchester University Press, 1999, pp. 173-196. Sobre el impacto del psicoanálisis y su temporada más intensa en España (1922-1931), ver GLICK, Thomas F.: «El impacto del psicoanálisis en la psiquiatría española de entreguerras», en SÁNCHEZ RoN, José Manuel (ed.): Ciencia y sociedad en España: de la Ilustración a la Guerra Civil, Madrid, Ediciones El Arquero/CSIC, 1988, pp. 205-221, y sobre la eugenesia, ÁlVAREZ PELÁEZ, Raquel: «Origen y desarrollo de la eugenesia en España», en SÁNCHEZ RON, Ibid., pp. 179-204.

13 VillenA, Luis Antonio de: "Álvaro Retana, en el abanico de la 'novela galante-decadente'«, Turia, $\mathrm{n}^{\mathrm{a}}$ 21-22 (1992), p. 21.

14 Santonja Gonzalo: La República de los libros, op. cit., p. 162.

is MARTín De LuCENAY, Dr. A.: Homosexualidad, op. cit., última cubierta.

Hispania, LXIV/3, núm. 218 (2004) 961-986 
Según aparece en la fotografía de la cubierta de sus libros, era un hombre de cerca de cuarenta años, bien vestido y con corbata, con un un aire de serio divulgador científico. Su obra se clasificaba según la editorial en los términos siguientes:

«Nada se ha hecho en el mundo en idioma castellano tan extraordinario en su género como esta colección, que constituirá una selecta y completísima biblioteca, integrada por 60 volúmenes que abarcarán el tema en todos sus múltiples aspectos» 16 .

A pesar de las cuestionables afiliaciones del autor y la excentricidad que le otorga Santonja en su descripción (este último llega a calificar los libros de Lucenay de "nada rigurosos, estridentes y sensacionalistas», cuya lectura siempre resulta "cuando menos divertida» ${ }^{17}$ ), pensamos que vale la pena tomarlos más en serio, no sólo por la impresionante envergadura de cuestiones cubiertas por esta biblioteca sino porque, además, constituye una colección de las más accesibles y de difusión de conocimientos prácticos para la vida diaria, ejemplares en este sentido de la exploración tan variada de la temática sexual del periodo. Rehuimos pues de los calificativos «conservador» o «radical», ya que el proceso de medicalización de la homosexualidad muestra que no es fácil, y resulta hasta contraproducente, imponer este criterio único; de hecho, muchas obras sobre el tema no eran sino una mezcla de posiciones incompatibles, subjetivas, progresistas y conservadoras. Situamos la obra de Lucenay en este complejo entramado.

En este sentido, la colección "Temas sexuales» cubre estudios sobre los órganos genitales ${ }^{18}$, el matrimonio ${ }^{19}$, el control de la natalidad ${ }^{20}$, hasta llegar a abarcar temas más inusitados si no "picantes» como los invertidos célebres ${ }^{21}$, la pornografía ${ }^{22}$, e incluso los ritos satánicos en la sexualidad ${ }^{23}$. Cada libro llevaba una fotografía de interés en la portada, a veces algo sugerente, y era común la

16 Ibid.

17 Santonja, Gonzalo: La República de los libros, op. cit., p. 174. Por otro lado, Alberto Mira, califica el pensamiento de Lucenay acerca de la homosexualidad de «incluso en la época, conservador» (MIRA, Alberto: De Sodoma a Chueca. Una bistoria cultural de la bomosexualidad en España en el siglo XX, Barcelona-Madrid, Egales, 2004, p. 189).

18 Martín De Lucenay, Dr. A.: Los órganos genitales, Madrid, Editorial Fénix (Temas sexuales, $\left.\mathrm{n}^{\circ} 1\right), 1932,94 \mathrm{p}$.

19 Martín De Lucenay, Dr. A.: El Matrimonio, Madrid, Editorial Fénix (Temas sexuales, $\mathbf{n}^{\circ}$ 19), $1933,95 \mathrm{p}$.

20 MARTín De LuCEnAY, Dr. A.: El control de la natalidad, Madrid, Editorial Fénix (Temas sexuales, $\left.\mathrm{n}^{\circ} 16\right), 1933,95 \mathrm{p}$.

21 MARTín De Lucenay, Dr. A.: Invertidos célebres, Madrid, Editorial Fénix (Temas sexuales, $\mathrm{n}^{\circ}$ 33), 1933.

${ }^{22}$ Martín De LuCEnAY, Dr. A.: La pornografía, Madrid, Editorial Fénix (Temas sexuales, $\mathrm{n}^{\circ}$ 39), $1933,80 \mathrm{p}$.

23 MARTín DE LuCENAY, Dr. A.: Los ritos satánicos, Madrid, Editorial Fénix (Temas sexuales), 1934. 
inclusión de varias láminas de buena calidad para ilustrar el argumento. Cada volumen valía de 1 a 1.25 pesetas y medía aproximadamente 15 por $20 \mathrm{~cm}$.

Desde la perspectiva de escritores como Martín de Lucenay y Gregorio Marañón, que intentaban proveer una visión que naturalizaba la homosexualidad, ésta se integraba dentro de las posibilidades sexuales de los seres humanos pero, a la vez, se patologizaba como un comportamiento sexual poco aceptable que habría que explicar científicamente.

Este juego entre la naturalización de lo que se entendía como un deseo perverso y su explicación científica es un motif muy común de la sexología del periodo. Implica que la homosexualidad siempre estaba moviéndose entre la periferia de la sexualidad y la expresión central o normativa de ésta que era la heterosexualidad ${ }^{24}$. ¿Cómo explicar la homosexualidad científicamente, descartando ya las sanciones religiosas o puramente morales, si no se entendía como una expresión «natural» (aunque equivocada) de la sexualidad animal o humana? Queda claro que uno de los propósitos de muchos divulgadores de conocimiento sexológico era el de combatir la influencia católica en el tema y abrir un nuevo horizonte científico, objetivo y por encima de mezquindades morales o religiosas.

\section{EL MARCO GENERAL DEL PENSAMIENTO DE LUCENAY EN CUANTO A LA HOMO- SEXUALIDAD}

El libro de Lucenay era el número 31 de su serie «Temas sexuales», publicándose en setiembre del año 1933. Aunque las publicaciones del doctor no eran organizadas explícitamente en temáticas o subdivisiones como, por ejemplo, el noviazgo y el matrimonio, o la fecundación y el parto, Homosexualidad apareció rodeado de unos números cuyos temas cabían dentro del cajón de sastre de las "perversiones» sexuales. Así, el número 29 introducía el tema de las perversiones sexuales, incluyendo el fetichismo, el exhibicionismo, el sadismo, el masoquismo, el vampirismo y la homosexualidad. El número posterior a Homosexualidad trató el safismo, el número 33 tocó el tema de los «invertidos célebres», el 35 el bestialismo y el 38 la sexualidad en los presidios, regimientos y barcos.

En general, el tono de estos opúsculos era, como hemos dicho, progresista. Daremos un ejemplo de esta actitud, sacado del número que Lucenay publicó acerca de las perversiones sexuales. En el prólogo de este libro, el autor remarcaba que los «viciosos» realmente no eran otra cosa que «enfermos» y que merecían un tratamiento como tal. Al relatar el caso de un exhibicionista, se lamentaba por el tratamiento recibido por éste que mostraba sus partes a niñas:

24 Este movimiento entre el centro y la periferia de la sexualidad, y el papel complementario de la homo y hetero sexualidad, es sostenido por SEDGWICK, Eve K.: Epistemología del armario, Badalona, Ediciones de la Tempestad, 1998.

Hispania, LXIV/3, núm. 218 (2004) 961-986 
«Fué brutalmente apaleado y condenado a no sé qué pena, condena verdaderamente monstruosa, no sólo con relación a su delito, sino en proporción con los orígenes de aquel acto, desde luego reprochable, pero merecedor de una apreciación más justa, o, por lo menos, más científica que la que prevaleció en el ánimo de sus juzgadores» 25 .

Homosexualidad, por lo general, sigue este marco, no necesariamente disculpando la práctica de la misma, sino intentando entenderla desde un punto de vista científico. Tratando tanto la homosexualidad masculina como la femenina, el libro se dividía en seis capítulos que cubren las raíces biológicas de la homosexualidad, la homosexualidad en el hombre, la homosexualidad en la mujer, las variedades de la homosexualidad, lo que el autor llama los sentidos y sus perversiones $\mathrm{y}$ "el falso homosexualismo».

Antes de examinar algunos de estos temas, Lucenay nos ofrece un prólogo que es de tanto interés como el contenido de los capítulos que le siguen ${ }^{26}$. En este prólogo, nos expone de forma sucinta una descripción del estado de la cuestión, explora los vínculos entre la moral y la ciencia y nos esclarece la motivación de su obra. Examinaremos brevemente cada uno de estos aspectos para entender mejor las secciones que siguen y el libro en su conjunto.

Lucenay abre el prólogo con una aseveración bastante atrevida para la épo$\mathrm{ca}$, aunque no sin antecedentes en la literatura sobre la homosexualidad o entre los movimientos de reivindicación de los derechos de los homosexuales (tanto del periodo contemporáneo como del periodo actual). En vez de presentar la homosexualidad como algo inaudito en la historia humana, Lucenay la naturaliza como una práctica constante a lo largo de los tiempos, aspecto que enfatizará en el capítulo sobre las variedades de la homosexualidad ${ }^{27}$.

Esta argumentación sería tildada ahora de «esencialismo» histórico, planteamiento que intenta encontrar la «homosexualidad» en los tiempos más remotos hasta hoy. Uno de los problemas de tal posicionamiento es que tiende a esconder las diferencias y los significados sociales y sexuales entre distintas expresiones «homoeróticas», aspecto combatido por el llamado social construccionismo ${ }^{28}$.

Esta vertiente histórica se ve, por otra parte, en obras menos abiertas a la naturalización de la homosexualidad, aunque de otra época, como la de Pedro Mata, que se refiere a la «sodomia» y la «pederastía» 29 . En la $5^{\text {a }}$ edición, se en-

25 MARTín De Lucenay, Dr. A.: Las perversiones sexuales, Madrid, Editorial Fénix (Temas sexuales), 1933 , p. 5.

26 «Prólogo del tema», en MARTín De LUCENAY, Dr. A.: Homosexualidad, op. cit., pp. 5-7.

27 Martín de LuCEnAY, Dr. A.: Homosexualidad, op. cit., pp. 57-68.

28 Sobre este debate hay una literatura extensa. Una primera orientación en castellano podría ser Cleminson, Richard y VÁzQUez GARCíA, Francisco: «Los Invisibles», op. cit.

29 Mata, Pedro: Tratado de Medicina y Cirugía Legal. Teoría y Práctica, Madrid, Carlos BaillyBaillière, $3^{\mathrm{a}}$ ed., 1857, p. 366. 
cuentran comentarios más detallados acerca de la "pederastía", pero con unas referencias históricas semejantes ${ }^{30}$. Por otro lado, se nota un fuerte impulso «primitivista» que supone que la homosexualidad es un atavismo que viene de tiempos y pueblos más primitivos o seres de más baja escala en el imperio de los animales. En este sentido, es interesante constatar de paso que en libros psiquiátricos o sexológicos, rara vez los homosexuales o lesbianas «hacen el amor». Más bien, si no entran descripciones más groseras, "se dedican a prácticas sexuales», o algo por el estilo. Lo mismo se decía de los «salvajes» que encontraban los antropólogos; tampoco eran capaces de amar ${ }^{31}$.

En este sentido, afirma Lucenay:

«En todo tiempo existieron homosexuales: la Biblia nos habla de Sodoma y Gomorra [...]. Ahora bien, si hemos de hacer caso a los etnólogos y antropólogos [...] resulta que la homosexualidad la practicaron los hombres primitivos como una consecuencia natural de la falta de mujeres y de los impulsos del instinto más irreprimible»32.

A pesar de este hecho, prosigue Lucenay, el tratamiento de los homosexuales por parte de la sociedad no ha sido igual a lo largo del tiempo. Según Lucenay, "hasta los comienzos del cristianismo» 33 , la homosexualidad no tuvo ninguna importancia para los comentaristas físicos o morales. Cuando aparece en el escenario histórico la religión cristiana, la homosexualidad mereció los castigos más severos y esto era porque «el sexo se condenaba en todas sus manifestaciones ${ }^{34}$. Este estado de cosas siguió hasta el siglo XIX, periodo en que la homosexualidad ya no se consideraba como «un síntoma degenerativo de la raza», como habían sostenido algunos, sino como un fenómeno «que no deja de tener unas bases naturales tal vez más sólidas que las de cualquiera otra perversión de los impulsos humanos» 35 .

Este tipo de comentario era típico de una publicación de divulgación sexológica "progresista». Este progresismo venía de tradiciones distintas, desde un posicionamiento más o menos liberal, hasta las de tilde izquierdista, marxista o anarquista. Todas las variedades progresistas, en cualquier caso, marcaban claramente sus distancias con las enseñanzas religiosas, queriendo naturalizar científicamente el saber sobre el sexo. Fue por esta razón que muchos tratados

30 MATA, Pedro: Tratado de Medicina y Cirugia Legal. Teoria y Práctica, Madrid, 5ª ed., 1874, p. 485.

31 Ver CARTER, Julian: «Normality, Whiteness, Authorship: Evolutionary Sexology and the Primitive Pervert», en RosarIo, V. A. (ed.): Science and Homosexualities, London, Routledge, 1997, p. 159.

32 Martín de LuCenay, Dr. A.: Homosexualidad, op. cit., p. 5.

33 Ibid.

34 Ibid.

35 Ibid., pp. 5-6. Es interesante constatar que Félix Martí Ibáñez construye la misma periodicidad en cuanto a las actitudes hacia la homosexualidad en sus "Consideraciones sobre el homosexualismo", Estudios (Valencia), nº 145, 1935, pp. 3-6.

Hispania, LXIV/3, núm. 218 (2004) 961-986 
sobre la cuestión sexual en los tiempos del franquismo envilecían los libros sexológicos del periodo republicano y de antes por ser, según ellos, destructores de la moral católica y de los buenos modales ${ }^{36}$.

Lucenay se pronunciaba también contra la mojigatería de los médicos que rehusaban hablar de la homosexualidad. El médico y el patólogo no tenían derecho, afirmó el autor, de actuar o inhibirse en nombre de la moral ya que no existía ninguna moral científica. La pretensión científica hacia la objetividad era desde luego corriente en comentaristas de diversas posiciones políticas en la época que se trata aquí. Mezclar la moral con la ciencia no hacía más que impedir la investigación razonada y científica. Mientras que la homosexualidad - proseguía Lucenay - era una muestra de alguna tara de tipo psicopático o biológico que podía traer consigo la locura, eso no impedía que hubiera individuos de talento que también eran invertidos.

La idea según la cual ciertas manifestaciones de la sexualidad como el onanismo o la homosexualidad tenían una conexión, como causa o como resultado, con la locura perduró hasta bien entrada el siglo XIX ${ }^{37}$. El cambio se produjo de acuerdo con los efectuados en toda la medicina de la locura ${ }^{38}$. Para un psiquiatra como César Juarros, las "perversiones sexuales» eran todavía síntoma de una locura por lo menos hasta $1919^{39}$. Por otra parte, la aproximación entre la homosexualidad y la brillantez o excentricidad se nota también en muchas obras apologistas de la homosexualidad o que argumentaban por su normalización ${ }^{40}$.

Una última constatación antes de entrar de hondo en la materia del libro: Lucenay emplea una mezcla de términos para describir el amor y el sexo entre individuos del mismo sexo. El título de su obra se refiere a la «homosexualidad» pero el autor utiliza el término «inversión sexual» y además se refiere a la «contrasexualidad» y a los "estados intersexuales», vocablos que se derivan de autores diferentes que escribieron acerca de la «homosexualidad» en el siglo XIX o XX. Aunque a primera vista tal variedad podría parecer hasta incoherente, no era nada excepcional para la época.

Mientras que el significado de cada uno de estos términos puede haber sido distinto en el momento de su invención, es posible que en los países receptores vinieran a ser más o menos intercambiables. Por supuesto, esta situación presenta una dificultad para el historiador. Por un lado, no se puede ser estrictamente nominalista, suponiendo que cada término traía un significado totalmente distinto, o describía una ruptura en el conocimiento acerca de la

36 Ver PÉRez LóPEZ, Jesús: El discurso pedagógico relativo a la sexualidad, op. cit.

37 Ver los cambios efectuados en los conceptos acerca de la conexión entre la homosexualidad y la locura a lo largo del siglo XIX y principios del XX en VÁzQUEZ GARCíA, Francisco: «El discurso médico y la invención del homosexual (España 1840-1915)», Asclepio (Madrid), vol. 53 (2001), $n^{\circ} 2$, pp. 143-162.

38 Álvarez Peláez, Raquel y Huertas, Rafael: ¿Criminales o locos?, Madrid, CSIC, 1987.

39 JuARros, César: La Psiquiatría del médico general, Madrid, Ruiz Hermanos, Editores, 1919.

40 Para el caso español, ver NIN FríAS, Alberto: Homosexualismo creador, Madrid, Morata, 1933. 
homosexualidad. Por otro lado, es preciso trazar los cambios que cada uso suponía en la descripción de esta expresión sexual. Aquí puede ser útil el comentario de Ian Hacking quien aboga por una teoría de «nominalismo dinámico» en que hay una relación de mutua construcción entre la persona o ente que «nombra» y la cosa o persona nombrada:

"The claim of dynamic nominalism is not that there was a kind of person who came increasingly to be recognized as bureaucrats or by students of human nature but rather that a kind of person came into being at the same time as the kind itself was being invented. In some cases, that is, our classifications and our classes conspire to emerge hand in hand, each egging the other on» 41 .

Además de utilizar una variedad de vocablos para describir la «homosexualidad», Lucenay emplea una diversidad de teorías para explicar su existencia que no coinciden necesariamente con los vocablos. No es de extrañar tampoco esta variedad de explicaciones etiológicas de la homosexualidad, desde las teorías congénitas hasta las teorías del contagio. En el caso de Lucenay, estas diferencias se expresan en términos de la «inversión» y la "perversión», respectivamente. Este último término correspondía más bien a una especie de vicio adquirido por falta de objeto sexual "correcto» o por «esnobismo», desembocando en muchos casos en una «falsa homosexualidad». El primero correspondería a la homosexualidad que se deriva de causas congénitas, biológicas o psicológicas, o una combinación de las dos, como veremos a continuación.

\section{LAS «RAÍCES BIOLÓGICAS DE LA HOMOSEXUALIDAD»}

Sin querer presentar la aportación de Lucenay como incoherente, tampoco se puede afirmar que la parte teórica de su exposición tenga una forma o contenido especialmente ordenada. En el primer capítulo que atiende a las «raíces biológicas de la homosexualidad», se recalca un gran número de teorías de autores conocidos tales como Ellis, Marañón, Hirschfeld, Hesnard y Bloch, y el lector se da cuenta inmediatamente de que el autor estaba al tanto del estado de la cuestión entre los grandes sexólogos europeos, aunque Lucenay, posiblemente en su afán de hacer su libro más accesible, no ofrece referencia alguna a los trabajos de estos médicos y sexólogos, aunque los cita a menudo. Tampoco se incluye ninguna bibliografía. Sin embargo, Lucenay no abogaba por una teoría u otra, aunque, como veremos más adelante, tenía cierta simpatía hacia las teorías del endocrinólogo español Gregorio Marañón.

Para introducir el tema de la homosexualidad, Lucenay abre su exposición con unas constataciones acerca de las diferencias sexuales entre los hombres y

41 HACKING, Ian: «Making Up People», en STEIN, Edward (ed.): Forms of Desire: sexual orientation and the social constructionist controversy, London-New York, Routledge, 1992, p. 78.

Hispania, LXIV/3, núm. 218 (2004) 961-986 
las mujeres. Este era un recurso común entre los sexólogos de la época para explicar muchos aspectos de la vida sexual humana y, en particular, lo que se entendía como una «anomalía» sexual como la homosexualidad.

De acuerdo con muchos tratadistas que escribían acerca de las diferencias sexuales, Lucenay afirmaba que todos los seres humanos tuvieron que pasar por una fase de «bisexualidad» inicial embrionaria, en que "gérmenes» de los dos sexos estaban presentes. Según algunos autores como Otto Weininger, cuya obra Sexo y Carácter se tradujo al castellano en 1902, o José de Letamendi ${ }^{42}$, este proceso dejaba restos de cada sexo en cada individuo, aunque esta idea remonta más allá del siglo XIX, por supuesto.

Como una extensión de esta teoría, muchos autores, incluso Lucenay, pensaban que la clave de la homosexualidad derivaba de este proceso ambiguo o inacabado donde reinaba la «confusión» de caracteres femeninos y masculinos. Si la sexualidad practicada por algunos individuos era «contraria» a la del sexo del cuerpo, la homosexualidad se podía explicar con base de unas causas fisiológicas (el sujeto realmente era del otro sexo) o por unas causas psíquicas (el mecanismo (hetero)sexual estaba de alguna forma dañado). La «sexualidad contraria» o, para ser más preciso, «la sensación de sexualidad contraria», era un término propuesto por Westphal en 1869 como síntoma de una condición neuropsicopática, asociada a taras hereditarias ${ }^{43}$. Con un funcionamiento sexual que se ejecutaba con toda «normalidad», un individuo adulto respondería eróticamente ante los estímulos del sexo «opuesto».

Lucenay se refiere también a las ideas de Kiernan, — de cuyas publicaciones en España no tenemos indicio-, que coinciden con las de José de Letamendi44. Kiernan, según la exposición que Lucenay hace, radica la homosexualidad en la bisexualidad del cuerpo humano (el hombre tendría los órganos rudimentarios de la mujer $)^{45}$.

Con la variedad de teorías barajadas, el aspecto divulgador de este libro de Lucenay, como el de sus otros volúmenes, queda claro al profundizarnos más en este primer capítulo. Una de las metas - y características- principales de este tipo de literatura era precisamente la de difundir el conocimiento acerca de la sexualidad y no necesariamente la de intentar solucionar las pugnas entre distintos posicionamientos teóricos. La falta de definición teórica, y cierta ex-

42 LeTAmend, José de: Curso de clínica general, Madrid, Imprenta de los Sucesores de Cuesta, 1894, vol. II, especialmente pp. 126-129 donde se menciona la «homoerastia» y la pederastia.

43 Ver Rosario, V.A.: The Erotic Imagination, London, Routledge, 1997, p. 84.

44 MARTín DE LuCENAY, Dr. A.: Homosexualidad, op. cit., p. 14. Es posible que Lucenay se refiera a la obra de Letamendi de 1889, Curso de patología general, Madrid, Establecimiento Tipográfico de Eduardo Cuesta, o a su Curso de Clínica general, op. cit.

45 Suponemos que el autor en cuestión es el doctor James G. Kiernan, de Chicago, mencionado en HANSEN, Bert: "American Physicians' "Discovery" of Homosexuals, 1880-1900: A New Diagnosis in a Changing Society", en RosenberG, C. E. y GolDEN, J. (eds.): Framing Disease: Studies in cultural bistory, New Brunswick, Rutgers University Press, 1992, pp. 114-115. 
presión de preferencia por algunas ideas, por lo tanto, saltan a la vista en este texto de Lucenay.

Al hacer un breve recorrido de las posibles etiologías de la homosexualidad - abarcando la homosexualidad congénita biológica, el efecto de la herencia de las intoxicaciones y las infecciones (en especial, el alcoholismo y la sífilis), una posible explicación degeneracionista ${ }^{46}$, y la influencia de los caracteres psíquicos-, Lucenay admite que «si se profundiza un tanto en estas explicaciones, inmediatamente nos sentimos transportados a la conclusión de que el homosexualismo es un verdadero enigma lo mismo en sus orígenes que en su desarrollo» ${ }^{47}$. Tal falta de concreción se arraiga en parte, según el autor, en la imposibilidad de demostrar adecuadamente la prepotencia de la adquisición o de la herencia en la constitución de la homosexualidad ${ }^{48}$.

En un momento, Lucenay diferencia entre la predisposición congénita y la herencia:

«Cuando en el individuo existe una predisposición congénita para la inversión sin que se adviertan antecedentes hereditarios $[\ldots] \gg 49$.

Para bastantes comentaristas de la época, los dos términos - la herencia y la predisposición- eran desde luego más o menos intercambiables ${ }^{50}$.

\section{¿HERMAFRODITISMO PSÍQUICO, INVERSIÓN SEXUAL U HOMOSEXUALIDAD?}

De esta gran variedad de teorías sexológicas barajadas, al autor le parecen más certeras y más propicias en cuanto a sus posibilidades explicativas las que se concentran en la «bisexualidad inicial» del embrión, proceso que resulta en caracteres sexuales opuestos en cada individuo. Sin emplear mucha cautela al momento de nombrar este fenómeno, Lucenay emplea los términos «hermafroditismo psíquico", "bisexualidad moral» e incluso se refiere a «estados intersexuales». Sin embargo, aunque no lo hace Lucenay, es necesario puntualizar que había cierta diferenciación entre estos términos tan dispersos, por lo menos en su uso original.

46 Sobre la noción de perversión en las teorías degeneracionistas, ver HUERTAS GARCÍA-ALEJO, $\mathrm{R}$., «El concepto de la «perversión» sexual», op. cit.

47 Martín de LuCEnay, Dr. A.: Homosexualidad, op. cit., p. 10.

48 Ibid., p. 14.

49 Ibid., p. 15.

50 Sobre las diferencias entre lo congénito y lo heredado conceptualizadas al principio del siglo XX, ver la discusión en HUERTAS, Rafael: «Niños degenerados. Medicina mental y regeneracionismo en la España del cambio de siglo», Dynamis (Granada), no 18 (1998), p. 172, y en CAMPOS MARín, Ricardo: «La teoría de la degeneración y la clínica psiquiátrica en la España de la Restauración», Dynamis, $\mathrm{n}^{\circ} 19$ (1999), pp. 429-456.

Hispania, LXIV/3, núm. 218 (2004) 961-986 
Esta multiplicidad de términos usados se esclarece, hasta cierto punto, cuando Lucenay desarrolla las diferencias entre hermafroditismo psicosexual y la inversión sexual. Aquí es necesario considerar un momento la genealogía de la idea del hermafroditismo y su conexión con la homosexualidad. Ya hemos dicho que muchos psiquiatras y sexólogos consideraban la homosexualidad como una expresión de alguna anomalía o confusión entre los sexos. En parte, esta idea viene de la comparación de la homosexualidad con el tener los dos sexos en el mismo cuerpo. De ahí, y de acuerdo con el cambio en la etiología de enfermedades de una economía que suponía irregularidades somáticas a una en que imperaban las psíquicas como causas o síntomas de la propia enfermedad, el hermafroditismo psíquico servía más o menos como una metáfora para explicar la homosexualidad.

Estos argumentos que relacionaban la homosexualidad con el hermafroditismo se pueden ver en la obra de Ellis, Krafft-Ebing y Ulrichs. En España, notamos que se desarrolla a lo largo del siglo XIX cierta aproximación entre el hermafroditismo y la homosexualidad. En 1857, Pedro Mata emplea una interpretación del hermafroditismo para luego pasar a hablar de la homosexualidad. Como otros̀ autores, en cuanto al hermafroditismo, Mata distinguía entre los casos en que había la unión de los dos sexos que, según él, en el ser humano no se producía, y los casos en que «el sugeto parece ser de un sexo a que realmente no pertenece» ${ }^{51}$.

De esta forma, Mata distinguía entre este hermafroditismo (que era más aparente que real) y la sodomía o pederastia que trataba a continuación. Lo que es diferente en el caso de Mata, en comparación con Lucenay o los psiquiatras y sexólogos extranjeros citados más arriba, es, sin embargo, primero, que sólo hay una asociación entre el hermafrodita y las prácticas sodomíticas o pederastas y no una conexión fisiológica o psíquica. Segundo, el que practica la sodomía o pederastia no parece tener ninguna personalidad especial (Mata no habla del «sodomita» y es solamente en ediciones más tardías que nombra el «pederasta») y no era concebido como hermafrodita psíquico ni nada por el estilo. La sodomía y la pederastia eran otras «aberraciones» como la mezcla de dos sexos en una misma persona ${ }^{52}$. Sin embargo, en una edición posterior de 1874 , se acerca la relación entre el hermafroditismo y la homosexualidad, y sin que vengan a ser lo mismo y que uno sea la antesala del otro, hay una sección más amplia sobre casos de hermafroditismo y una descripción más detallada no sólo de las prácticas sexuales de los pederastas, que él nombra ya como un grupo identificable, sino también de sus características físicas, sus ademanes y sus gustos.

51 Mata, Pedro: Tratado de Medicina y Cirugía Legal, $3^{\mathrm{a}}$ ed., op. cit., vol. I, p. 260.

52 Esta expansión en el estudio de Mata será debida casi indudablemente a la llegada de la obra de Ambroise Tardieu, a quien Mata cita extensamente. Para estos cambios, ver MATA, Pedro:

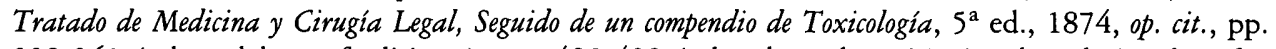
339-361 (sobre el hermafroditismo), pp. 485-492 (sobre la pederastia). La obra de Tardieu fue traducida al castellano en 1863 como Estudio médico-forense de los atentados contra la bonestidad.

Hispania, LXIV/3, núm. 218 (2004) 961-986 
Más tarde, ya en el siglo XX, en la obra del higienista Luis Comenge, aunque se detecta una distinción entre el hermafroditismo «absoluto», anatómico y funcional, y el hermafroditismo aparente, ya hay un desliz entre el hermafroditismo y la homosexualidad ${ }^{53}$. Era posible que el hermafroditismo como error de conformación recayera «en individuos á quienes el vulgo bautiza con el nombre de maricas, de viragos ó marimachos. En este caso, la confusión puede ser más honda, grande y perturbadora» ${ }^{54}$. La asociación entre el hermafrodita y el homosexual ya queda forjada.

¿Cuál es la posición que Lucenay toma respecto a estas teorías? Él mantiene, e incluso refortalece la asociación entre el hermafroditismo y la homosexualidad pero le da un giro interesante. El hermafrodita psíquico (el hermafrodita «aparente» de Mata y Comenge), ya es otro ser, capaz de amar a los dos sexos. La persona que ama únicamente a su mismo sexo ya es otra creación: el invertido sexual. Lucenay lo razona así:

«El hermafroditismo psicosexual es una cosa y la inversión es otra. En el primer caso, según las teorías expuestas, se trata de individuos que lo mismo se sienten inclinados hacia las personas de su sexo que a las del sexo contrario esto es, que tienen tantas partes psíquicas de varones como de hembras, no importando para nada que sus blándulas [sic] fundamentales sean testículos u ovarios» 55 .

En este aspecto por lo menos, Lucenay coincidía con César Juarros que escribía en 1914 que el «hermafrodismo psíquico» denominaba «el hecho de que un individuo tenga intimidades genitales con personas de los dos sexos», es decir, lo que podríamos denominar hoy día, bisexualidad ${ }^{56}$. Juarros incluía el hermafrodismo psíquico junto con otros «trastornos» en el ser humano como el uranismo, la masturbación, la frigidez, y el masoquismo, bajo la sección del libro dedicada a los síntomas de las enfermedades mentales. Hay que notar que el «pseudohermafroditismo» era otra cosa en la mente de algunos psiquiatras tempranos como Krafft-Ebing. Aunque había, como hemos dicho, una equiparación entre el hermafroditismo y la homosexualidad, "pseudo-hermafroditismo» parece haber sido un concepto más fisiológico, sin consecuencias necesariamente para las preferencias del sujeto. Según un autor, el pseudo-hermafroditismo se producía desde un proceso erróneo en la fijación de los caracteres sexuales (que se haría a partir de la fusión del esperma y del huevo y de la acción posterior de las glándulas). A partir de este proceso defectuoso, nacían no sólo los pseudo

53 COMENGE, Luis: Generación y crianza ó higiene de la familia, Barcelona, José Espasa, s.f.

54. Ibid., p. 147. Para ambos escritores, el tema del hermafroditismo lindaba con el estudio de las monstruosidades, la Teraselgia. Sobre la relación entre los monstruos y las figuras aberrantes de la sexualidad, ver FOUCAUlt, Michel: Los Anormales, Madrid, Akal, 2001, especialmente pp. 57-126.

ss MARTín De LuCEnAY, Dr. A.: Homosexualidad, op. cit., p. 13.

56 JUARros, César: Psiquiatría forense, Madrid, Imprenta de Antonio Marzo, 1914, p. 56. 
hermafroditismos de la especie humana, sino también «los enfriamentos eróti$\cos$ y las aberraciones e inversiones» ${ }^{57}$.

Queda claro que el vínculo entre el hermafroditismo y la inversión sexual todavía estaba vivo por las fechas en que se escribió este libro. Es importante notar, además, una posible coincidencia de Lucenay con las ideas de Freud. Freud hizo la crítica de la teoría según la cual el hermafroditismo psicológico era una causa directa de la homosexualidad en sus Tres Ensayos (1905) ${ }^{58}$.

En cuanto a la inversión, aquí «predominan los caracteres psíquicos del sexo contrario» ${ }^{59}$. Esta nueva denominación es una especie de combinación de los caracteres del hermafrodita, en cuanto a la combinación de los dos sexos, y del pederasta que ya era identificable por sus prácticas, gustos y apariencia física. La «inversión sexual», siendo una teoría híbrida, combina de manera ecléctica aspectos de otras muchas teorías que circulaban en la época ${ }^{60}$.

Sin embargo, es interesante notar que respecto al uso de los términos invertido y homosexual, Lucenay no coincide de algún modo con Juarros quien en un libro suyo de 1919, define la inversión sexual como la «homosexualidad» completa - en sus palabras aquélla era «una modalidad extrema, exagerada de la homo-sexualidad» ${ }^{61}$. La homosexualidad en este caso es una fase que tiene su punto de partida en la infancia «bisexual», arguye Juarros. Y el autor apunta que «son varios los homosexuales que además tienen relaciones sexuales con mujeres" ${ }^{62}$. Podemos detectar en debates de este tipo los momentos cruciales de la formación de estos conceptos, conceptos que no tienen, por lo visto, ninguna rigidez, aunque en ellos sí que se pueden notar rasgos que perduran o que son transformados.

En vez de un proceso lineal que va desde el sodomita hacia el invertido para desembocar en la figura del homosexual (propuesta que se podría denominar la vulgata foucaultiana $)^{63}$, lo que se ve en los casos arriba analizados es la complejidad. Entre otros autores, George Chauncey ha ilustrado cómo, en el caso de Estados Unidos (o, por lo menos, de Nueva York), el propio término «inversión sexual» describía una amplia gama de prácticas no conformes con el sexo biológico de la persona que las mostraba. No significó, según el mismo autor,

57 Gómez OCAÑA, José: El sexo, el bominismo y la natalidad, Madrid, Editorial Saturnino Calleja, 1919, p. 42.

s8 Ver VÁzQuez García, Francisco y Moreno Mengíbar, Andrés: Sexo y Razón, op. cit., p. 205.

59 MARTín De LuCENAY, Dr. A.: Homosexualidad, op. cit., p. 14.

60 ROSARIO, V. A.: The Erotic Imagination, op. cit., p. 70. El autor nota que fue Arrigo Tamassia quien empleó primero el término «inversione dell'istinto sessuale» en 1878 y que luego fue vertido a otras lenguas.

61 JuArros, César: La Psiquiatría del médico general, op. cit., p. 91.

62 Ibid.

63 Compárese nuestra crítica en VÁzquez G., Francisco y Cleminson, Richard: «Democracia y cultura sexuales. La irrupción de la homosexualidad en la escena política española», Er. Revista de Filosofía, na 32 (2003), pp. 129-166. 
necesariamente la «desviación» en términos de sexualidad; podía describir en el hombre ciertos rasgos personales, como la voz, la ropa, el pelo, algo «femeninos». Sin embargo, en España, la «inversión sexual» habría ido adquiriendo el significado sexual que tanto Juarros como Lucenay describen.

Hemos sugerido en otro lugar que la inversión sexual que describía ya prácticas sexuales y ciertas características físicas y "psíquicas» se estaba forjando justamente en los años veinte y treinta en España, periodo en que algunos comportamientos en los hombres eran «resignificados» para denominar las prácticas sexuales entre hombres ${ }^{64}$. Este proceso, por incompleto y discontinuo que fuera, parece haberse consolidado, en el caso de Juarros, en la década de 1910 y, en el caso de Lucenay, a principios de la década de los 30. Es posible que el término "homosexual», para denominar todo el aparato de prácticas sexuales con sus etiologías psíquicas o biológicas, tuviera mucho menos aceptación en estos medios en España.

\section{¿LA INFANCIA COMO CLAVE DE LA SEXUALIDAD «DESVIADA»?}

La psiquiatría española de la época incorporó a su ideario la teoría del desarrollo sexual, con sus etapas de desenvolvimiento desde la infancia hasta la adultez. Desde esta perspectiva, las desviaciones sexuales en la infancia son aceptadas como comportamientos normales ya que el niño se considera «perverso polimorfo». Sin embargo, para que esas prácticas desviadas pervivieran hasta la edad adulta, era necesario que el individuo tuviera algún tipo de predisposición hacia la morbosidad y de ahí nace el concepto de la «infancia degenerada» que acusaba un debilitamiento congénito en los centros nerviosos debido a impresiones traumáticas recibidas. De esta forma, la psiquiatría española, la disciplina con más influencia en la construcción de las perversiones en la época, fundía ciertos preceptos organicistas (degeneracionistas, o hereditarios) con las bases del psicoanálisis ${ }^{65}$. Así, en la psiquiatría y la sexología española:

«El sexo infantil se convierte en clave hermenéutica para descifrar el origen, las causas de las anomalías en la edad adulta: las desviaciones patológicas actuales no son sino síntomas de un desarrollo patológico alterado, ligado a la precocidad infantil, a una niñez mal influida y peor encauzada. La vesania sexual no es simplemente un cuadro clínico de signos; se trata de una profundidad, enclavada en la historia del individuo y de la raza, en la ontogenia del sujeto y en la filogenia de la especie» 66.

64 Cleminson, Richard: «Male Homosexuality in Contemporary Spain: Signposts for a Sociological Analysis», Paragraph: A Journal of Modern Critical Theory, vol. 22 (1999), $\mathrm{n}^{\circ} 1$, pp. 35-54.

65 Este párrafo sigue la línea argumentada en VÁzQuez GarCía, Francisco y MORENO MENGíBAR, Andrés: Sexo y Razón, op. cit., pp. 161-164.

66 Ibid., p. 126.

Hispania, LXIV/3, núm. 218 (2004) 961-986 
Tal vez, lo sorprendente de la exposición de Lucenay no es tanto que él haya entendido la sexualidad infantil de acuerdo con estas premisas sino que, además de encontrar en la infancia los signos típicos de «inversión sexual» u «homosexualidad», habla de niños y niñas homosexuales, algo bastante inaudito para la época ya que reconocer la bomosexualidad infantil o adolescente como práctica ya establecida rompe no sólo con la idea de la llegada de la madurez sexual en la adultez sino también cierra cualquier posibilidad de "curar» al sujeto de su homosexualidad.

Por supuesto, Freud, entre otros, enfatizaba la importancia de la sexualidad infantil en la génesis de todas las "perversiones». Sin embargo, reconocer que hay chicos y chicas homosexuales, aunque Lucenay no especifica su edad, es algo que incluso hoy no se ha aceptado del todo. Se recuerdan en este sentido los debates acerca del supuesto proselitismo homosexual en la enseñanza secundaria que todavía giran en torno a la Cláusula 28 introducida por los conservadores británicos bajo Margaret Thatcher en los años 80 , debates que, implícita o explícitamente, no reconocían la existencia de jóvenes homosexuales con menos de 18 años, edad a partir de la cual las relaciones masculinas homosexuales eran legales (ahora, la ley británica especifica a los 16 años).

El recurso que Lucenay emplea para respaldar esta idea descansa en su concepto de «homosexualidad verdadera». Ésta se caracteriza por su temprana y espontánea aparición, aspecto que responde, para él, a una predisposición natural. Aunque el ambiente puede influir para retrasar su aparición, Lucenay no sugiere ningún tipo de disciplina o gobierno de la infancia para impedirla, en contraste con otras obras publicadas al principio del siglo XX por autores como Bugallo Sánchez o Suárez Casañ, por ejemplo.

En La delincuencia infantil (Madrid, Morata, 1931), Bugallo Sánchez no nombra la homosexualidad como delincuencia en sí, sino que alude a unas perversiones sexuales amorfas - precocidad sexual, el onanismo y la mala influencia de las prostitutas. Como profilaxia, aboga por una limpieza del medio ambiente en que el niño nace y crece y un reparo hacia lo que los padres pueden ofrecer como herencia a su progenie.

El posicionamiento de Lucenay es interesante ya que marca sus distancias con otros que patologizaban más a la homosexualidad y que presentaban sus soluciones para acotar su establecimiento tanto en el individuo como en la sociedad. La homosexualidad, por lo menos en su forma «verdadera», quiérase o no, se establece como un rasgo psicológico inmutable. Sin embargo, como veremos a continuación, la homosexualidad que no es "verdadera», que es un «falso homosexualismo», no se constituye ni siquiera como un rasgo congénito ni psicológico sino como una adquisición por otros motivos.

Para resumir: el sentido principal de este primer capítulo de Homosexualidad es que mientras se puede describir el desarrollo de la inversión congénita no se pueden identificar con certeza las causas de la homosexualidad; no se puede 
resolver la cuestión de su "patogenia auténtica» ${ }^{67}$. Lucenay reconoce que ninguna teoría «ha sido suficiente para dar la clave exacta de solución» ${ }^{68}$, a pesar de argüir que la teoría más célebre y la más moderna, basándose en la endocrinología, es la de Marañón. Según «nuestro profesor Marañón», las causas de la homosexualidad en parte tienen base en las glándulas internas aunque también es necesario referirse a la morfología del sujeto y hasta de sus órganos sexuales.

A pesar de esta falta de concreción en cuanto a las causas de la homosexualidad, Lucenay sí da primacía a unas causas biológicas o congénitas, para la homosexualidad "verdadera», sobre otras teorías que apuntạn a la adquisición de la homosexualidad (como si fuera un contagio) por vicio o falta de contacto con el sexo "opuesto». La idea del "contagio» homosexual no es nueva. Habrá tenido un empuje desde esas ciencias penales que enfatizaron la transmisión de prácticas delictivas. Por ejemplo, dos autores franceses admiten que el contagio ocurre más fácilmente en los que son «degenerados» o que están «predispuestos» al mismo sin especificar cómo esta degeneración o esta predisposición ocurre ${ }^{69}$.

Como veremos más adelante, este posicionamiento le permite a Lucenay dos cosas: primero, argüir que la homosexualidad "verdadera» no se debe castigar ya que de una forma u otra es «congénita» o existe una predisposición a ella, y, segundo, le permite construir su propia argumentación para desvirtuar a los apologistas de la homosexualidad - como el escritor francés André Gide- que presentan la homosexualidad como totalmente natural y además benéfica. De esta forma, el pensamiento de Lucenay, por lo menos en este respecto, coincide con el de Marañón y de Jiménez de Asúa unos pocos años antes ${ }^{70}$.

\section{LA HOMOSEXUALIDAD EN EL HOMBRE: LOS VIRILES, LOS ARISTOCRÁTICOS Y LOS AFEMINADOS}

En la sección siguiente del libro, Lucenay se concentra en las manifestaciones personales y culturales de la homosexualidad en el hombre. Ante descripciones de este tipo, hay que mantener por supuesto una postura muy crítica. Es posible que lo que Lucenay describía reflejara una representación verídica del mundo homosexual de la época. Sin embargo, el deseo de encajar lo observado en las teorías médicas y psiquiátricas a menudo determinan «lo que se ve» y las

67 Martín de Lucenay, Dr. A.: Homosexualidad, op. cit., p. 23.

68 Ibid., p. 24.

69 Vigouroux, A. y JonQuelier, P.: El contagio mental, Madrid, Daniel Jorro, 1906 (traducción del Dr. César Juarros).

70 Ver Cleminson, Richard: «A. Hernández Catá's El Angel de Sodoma (1929): queer narratives, the threat and promise of modernity and the medico-legal defence of male homosexuality in Spain», en CARLING, A. H. (ed.): Globalization and Identity, London, I.B. Tauris, 2004.

Hispania, LXIV/3, núm. 218 (2004) 961-986 
categorías que los expertos construyen; no son una descripción de la verdad, sino que son un intento de construir la verdad.

En su descripción del homosexual masculino, el autor marca sus diferencias con lo que él presenta como la opinión popular. Lucenay mantiene que sería un error pensar que el homosexual masculino podría identificarse con facilidad por sus signos exteriores. Asegura que «en los tiempos presentes [...] es más difícil cada vez precisar quiénes son homosexuales a juzgar por sus rasgos y ademanes» ${ }^{71}$. Afirma que la homosexualidad es cada vez más compatible con los deportes y profesiones viriles como el boxeo, el toreo, el fútbol o ser cargador de muelle. «[E]l tipo afeminado de que nos hablan los literatos picarescos de otras épocas, está llamado a desaparece[r] $\gg^{72}$, y el homosexual ha logrado disfrazarse tanto que resulta difícil distinguirle de la masa general. Los más evidentes, los que tienen alma de mujer en cuerpo de hombre, que se desmayan con el aroma de una flor, han quedado para los que se complacen en imitar «los gestos, los ademanes y hasta las vestimentas femeninas, y que tanto abundan, por ejemplo, en el tenebroso y sucio Barrio Chino del quinto distrito barcelonés y en algunas ciudades de Andalucía» ${ }^{73}$.

En esta misma sección, Lucenay discrepa con el trabajo de dos sexólogos de renombre, Hirschfeld y Bloch, que afirmaron que la homosexualidad tenía mucho que ver con la afeminación, crítica que, paradójicamente, coincidiría con unos apologistas de la homosexualidad viril como Gide, Brand y Friedländer ${ }^{74}$.

Si hubo un cambio de este tipo, conformaría con lo que el escritor norteamericano George Chauncey ha sugerido en el caso de Nueva York por las mismas fechas. De ser así, este cambio podría sugerir alguna transformación no sólo en lo que se refiere a la expresión de la homosexualidad sino también en términos de la masculinidad y, por ende, de las relaciones entre los géneros. Además, tal vez haya influido también en este cambio una cuestión de clase. Es posible que entre dos de los modelos posibles - el modelo del homosexual aristocrático o «dandy» y el marica pintarrajeado- se forjara otro, más «masculino», más difícil de identificar frente a los heterosexuales ${ }^{75}$. Este «tercer» modelo podría ser lo que han llamado el «maricón», el homosexual «activo» y que puede pasar por heterosexual ${ }^{76}$.

71 Martín De LuCenay, Dr. A.: Homosexualidad, op. cit., p. 27.

72 lbid.

73 Ibid., pp. 27-28.

74 Ibid., p. 28. Para las ideas de Gide, ver su Corydon, libro que Lucenay critica más adelante en las páginas 34-35 y 40. Para Brand y Friedländer, ver OOSTERHUIS, Harry: Homosexuality and male bonding in pre-Nazi Germany, New York-London, Haworth Press, 1991.

75 Sobre la homosexualidad literaria y esteta, ver MIRA, Alberto: «Modernistas, dandis y pederastas: articulaciones de la homosexualidad en la edad de plata», Journal of Iberian and Latin American Studies (Bristol), vol. 7 (2001), $\mathrm{n}^{\circ}$ 1, pp. 63-75.

76 A propósito del marica y del maricón y sus diferencias, ver GUASCH, Oscar: La sociedad rosa, Barcelona, Anagrama, $2^{a}$ ed., 1995. 
La división que Lucenay propone entre los homosexuales afeminados, fácilmente identificados, y los más viriles (que el autor toma de la distinción que hace Bloch entre dos tipos de uranistas, los «uranistas viriles» y los «uranistas afeminados», «equivalentes al feminismo psíquico y al feminismo corporal», respectivamente ${ }^{77}$ ), le permite otro paso en su exposición acerca de la etiología de la homosexualidad y es aquí donde, por fin, encontramos una clave del pensamiento del autor.

Para él, el afeminamiento físico evidencia la existencia de síntomas degenerativos, o de un funcionamiento anormal de las glándulas testiculares en el hombre ${ }^{78}$. En estos casos, la inversión tiene una base fisiológica, y no psíqui$\mathrm{Ca}^{79}$. Como veremos a continuación, a grandes rasgos, la base fisiológica responde, para Lucenay, a la homosexualidad de más arraigo «natural» (recuérdese que para él no se ha podido saber si la homosexualidad resulta ser algo congénito o no) ${ }^{80}$, y la otra, la psíquica, a la homosexualidad adquirida ${ }^{81}$.

Es decir, para él, la «homosexualidad verdadera» tiene una base congénita y psíquica y la «homosexualidad falsa» podía tener sólo la parte psíquica. Al intentar perfilar más claramente el enmarañado del pensamiento de Lucenay acerca de este tema, es importante tratar de entender las principales líneas teóricas de su exposición y relacionarlas con las ideas existentes del tiempo. Sin embargo, soy consciente de no construir una versión de los planteamientos del autor que otorguen demasiada coherencia a su exposición. Que quede claro: la tarea aquí no es imbuir a Lucenay con una consistencia que, de hecho, él mismo no sabe lucir.

\section{EL FALSO HOMOSEXUALISMO}

El libro de Lucenay, que carece de una estructura bien definida, para finalizar, trata lo que el autor llama el «falso homosexualismo». Para entrar en el tema, él afirma que hay muchos homosexuales que lo son porque la naturaleza los dispuso así pero hay otros que lo son por vicio, que han adquirido la homosexualidad, o porque son heterosexuales viciosos. Para Lucenay, estos «falsos homosexuales» merecían el desprecio de la sociedad y la atención de la policía ${ }^{82}$, tratamientos de los cuales los «verdaderos homosexuales» serían exentos.

A pesar de que tales falsos homosexuales serían un producto de la sociedad supercivilizada - la crítica hacia la sociedad sobre-civilizada se nota en algunos

77 Martín de Lucenay, Dr. A.: Homosexualidad, op. cit., p. 31. Aquí el «feminismo» significaba los rasgos o apariencias femeninos.

78 Ibid., p. 29.

79 Ibid., p. 30.

80 Ibid., p. 35.

81 Ibid., pp. 29-30.

82 Ibid., p. 79.

Hispania, LXIV/3, núm. 218 (2004) 961-986 
escritores a fines de siglo XIX como Spengler, Nordau y Max Weber, escritos en que se ve claramente cierta ansiedad hacia los cambiantes papeles de género- , prosigue el autor, hay que recordar que todo individuo está formado por un $50 \%$ de masculinidad y un $50 \%$ de feminidad y por eso es casi imposible distinguir entre el homosexual falso y el congénito ${ }^{83}$.

Esta afirmación puede derivar, por ejemplo, de la obra de Westphal, arriba citada o de José de Letamendi, el catedrático de la Universidad de Madrid. El doctor Gómez Ocaña cita a Letamendi a este efecto («el sexo contrario late en cada persona, dominado, no extinguido»), cita que toma de la comunicación de Letamendi en Roma titulada, según Gómez Ocaña, y no corregimos el italiano, «La verità sulle aberrazioni ei delitti n'ell ordini sexuale» $(1894)^{84}$.

Esta «bisexualidad» a la que alude Lucenay le permite extrapolar un número de situaciones en los individuos «indiferenciados» sexualmente (en los cuales, se supone, que la lucha entre los dos sexos ha dado resultado equívoco). En estos casos, puede arraigarse la mala semilla de la sexualidad invertida. Para indicar este proceso, Lucenay relata casos de niños y niñas masturbados por adultos que luego se convierten en homosexuales ${ }^{85}$. En estos casos, afirma nuestro autor, queda claro que la homosexualidad es adquirida.

Más adelante, dice que el (falso) homosexualismo se puede reprimir más fácilmente en una edad mayor (compárese este argumento con su aseveración según la cual la homosexualidad, y la heterosexualidad, es para toda la vida, si son «congénitas»). Es más, cuando se trata de individuos bien constituidos intelectualmente, la homosexualidad es adquirida y, en estos casos, el autor vuelve a enfatizar la relación entre la homosexualidad y la gente más sensible, artística o viciosa, es decir, según él, los estetas y los juerguistas. Entre estas personas, el contagio sería común ${ }^{86}$. La implantación de la homosexualidad depende, en todo caso, del tiempo que duran las prácticas sexuales entre individuos del mismo sexo. En los presidios pueden arraigarse fácilmente y por larga duración y los hombres y mujeres «al cabo de varios años de práctica constante llegan a perder el instinto de la heterosexualidad hasta el extremo de no diferenciarse en nada de los invertidos congénitos ${ }^{87}$.

Parece, por lo tanto, que el autor concede un alto grado de importancia a las tesis medio-ambientales acerca de la homosexualidad e incluso del contagio de la misma y al factor degenerativo que se acumula en el ser humano. En cuanto a la degeneración, hay que recordar que se concebía, por lo menos en la obra de Morel quien planteó primero esta condición en la época contemporánea, como algo que podía ser congénito o adquirido, completo o incompleto,

\footnotetext{
83 Ibid.

84 Gómez OCAÑA, José: El sexo, el hominismo y la natalidad, op. cit., p. 42.

85 MARTín DE LUCENAY, Dr. A.: Homosexualidad, op. cit., p. 80.

86 Ibid., pp. 82-83.

87 Ibid., p. 82.
} 
susceptible de mejoras o incurable ${ }^{88}$. En una exposición que sugiere la plasticidad sexual completa, Lucenay relata el caso de un médico que se contagió de homosexualismo después de entrevistarse con un paciente que le describía detalladamente sus prácticas sexuales ${ }^{89}$.

Para Lucenay, entonces, parece operarse una especie de fusión de los homosexuales que lo son por «naturaleza» con los que lo son por «vicio» y en la cual es imposible distinguir entre los homosexuales de largo tramo y los recién «convertidos». Dice el autor que el que llega a la inversión completa después de la heterosexualidad no se diferencia en nada del homosexual congénito de larga experiencia. De esta manera, «la seducción, esto es, la sugestión, puede ejercer sus efectos independientemente de la predisposición del individuo» ${ }^{\circ 0}$. Es más, la homosexualidad, de acuerdo con una versión de las teorías degeneracionistas o incluso hereditarias, puede pasar a ser característica congénita del sujeto si se practica durante mucho tiempo:

«No hay duda de que [la homosexualidad] puede empezarse por curiosidad y que esta curiosidad suele dar lugar al nacimiento de un hábito que en individuos de carácter débil llega a arraigarse a tanta profundidad como lo esté cualquier otra anormalidad congénita: pero esto precisamente es el vicio, la perversión, lo que carece de bases naturales como, al fin y al cabo, es la inversión congénita»91.

¿Será que esta perversión, una vez integrada en el hombre puede venir a ser la inversión completa, la inversión congénita? En el esquema de Lucenay, parece que sí.

\section{CONCLUSIONES}

El libro de Martín de Lucenay es típico de la estirpe de obras de divulgación de temática sexual que aparecieron en España a principios del siglo XX. Homosexualidad se posicionó conscientemente en relación con las aportaciones de otros sexólogos, tanto españoles como extranjeros, tales Marañón, Hesnard, Ellis y Krafft-Ebing, por las continuas referencias a la obra de estos escritores. A pesar de reconocer los límites de las posibilidades explicativas de esta ciencia -recuérdese que Lucenay escribía que la homosexualidad era «un verdadero enigma lo mismo en sus orígenes que en su desarrollo» ${ }^{22}$-, la sexología nunca

\footnotetext{
88 Ver PICK, Daniel: Faces of Degeneration: A European Disorder, c. 1848-c.1918, Cambridge, Cambridge University Press, 1989, p. 48, nota 33 (donde Pick cita a Morel al efecto).

89 Martín De Lucenay, Dr. A.: Homosexualidad, op. cit., p. 83. Me refiero al caso descrito en el epígrafe.

90 Ibid., p. 85

91 Ibid.

92 Ibid., p. 10.

Hispania, LXIV/3, núm. 218 (2004) 961-986
} 
fue cuestionada como recurso hermenéutico para explicar y entender la homosexualidad.

Este recurrir a las ciencias sexológicas para explicar tanto la vida sexual «normal» como sus «aberraciones» era característico de una época en que la ciencia en todos sus matices se presentaba como hermenéutica para profundizar en el secreto del sexo. Presentada como una ciencia necesaria y legítima, la sexología imbuyó a muchos campos de conocimiento y de vida cotidiana en España en las tres primeras décadas del siglo XX. Pero esta relación no fue unidireccional. Lucenay. combinaba anécdotas, casos clínicos y la realidad de la cultura de la calle para convalidar sus propósitos sexológicos.

Homosexualidad muestra la plétora de términos corrientes en la sexología para describir el fenómeno de la «homosexualidad». Hasta cierto punto, vemos un uso prácticamente intercambiable entre los diversos términos, pero con preferencia de «inversión sexual», «homosexualismo» y «homosexualidad» por encima de «hermafroditismo psíquico» o «sexualidad contraria». Tal variedad de términos nos muestra como la sexología por estas fechas en España, por lo menos en cuanto a la homosexualidad, era una ciencia en construcción, un foro de debate.

George Chauncey, en un conocido ensayo, ha demostrado que la «inversión sexual» no denotaba lo mismo que la «homosexualidad»93. Mientras que la primera se concentraba en una amplia gama de comportamientos no acordes con el género de la persona, la homosexualidad se refería más bien al objeto sexual. Para Chauncey, la diferenciación del deseo homosexual respecto al comportamiento desviado en términos de género refleja una reconceptualización importante en la naturaleza de la sexualidad humana, su relación con el género y su papel en la definición social del yo. Alrededor de 1900, Ellis, entre otros, habrá intentado redefinir la inversión más estrechamente y en términos sexuales, diferenciándola del travestismo y de otras formas de inversión de género. El objeto sexual vino a ser lo más importante y un hombre podía ser pasivo sin ser afeminado. El incrementado uso del término «homosexual» reflejó este cambio.

Sin embargo, en el caso de España, parece ocurrir algo diferente. Parece que el concepto de la «inversión sexual» describía, en las fechas en que escribía Lucenay, tanto la «desviación» en el papel de género como la afinidad a actos sexuales con personas del mismo sexo. La inversión sexual vino a ser, hasta por lo menos el principio de los años treinta, el término dominante, coincidiendo con la «homosexualidad" o el «homosexualismo».

Hemos dicho en otro lugar que los años veinte eran un periodo de visibilidad y de identificación de la homosexualidad masculina en España. Es muy difícil puntualizar el origen de las dos caras de la misma moneda de la homosexualidad que se han mencionado. ¿Se hacía más visible la homosexualidad por unos proce-

93 Chauncey, G.: «From Sexual Inversion to Homosexuality: The Changing Medical Conceptualization of Female 'Deviance'«, en Peiss, K. y Simmons, C. (eds.): Passion and Power: Sexuality in History, Philadelphia, Temple University Press, 1989, pp. 87-117. 
sos culturales fuera de la ciencia sexológica? ¿Fue identificada a raíz de un afán sexológico de clasificarlo todo y de afirmar sus propias teorías? Tal vez sea equivocado buscar el origen en este sentido. Más productivo sería preguntar equé relaciones de poder se establecían entre el homosexual y las ciencias sexológicas a partir de su identificación? Un efecto inmediato sería el intento de marcar diferencias —etiológicas, morales, y hasta jurídicas - entre distintos tipos de homosexuales, creados, a la vez, por el propio discurso sexológico.

La fuerte diferenciación que Lucenay establece entre la homosexualidad congénita y la adquirida sería acompañada de consecuencias importantes para los sujetos homosexuales. Si la homosexualidad fuera congénita, Lucenay proponía que se dejara a los homosexuales más o menos en paz; por lamentable que fuera su condición, era natural, dentro de las nuevas etiologías de la perversión. Si fuera adquirida - y, por lo tanto, «falsa»- habría que intervenir en lo jurídico y penal para frenar su proliferación. En este proceso de gestión del sujeto la sexualidad se establece como clave de la representación y de la fortuna jurídica y legal del homosexual. En esta vigilancia de la sexualidad que busca la verdad del sexo homosexual y crea las categorías "verdadero» y «falso», la sexología reafirma otra vez su clave como mediadora de destinos.

Por eso, vemos que el «homosexual», del tipo que fuera, era una figura importante en la configuración de los límites entre la sexualidad aceptable y la sexualidad inaceptable, entre lo congénito y lo adquirido y entre la ciencia y la cultura más amplia de la España de principios del siglo XX. 